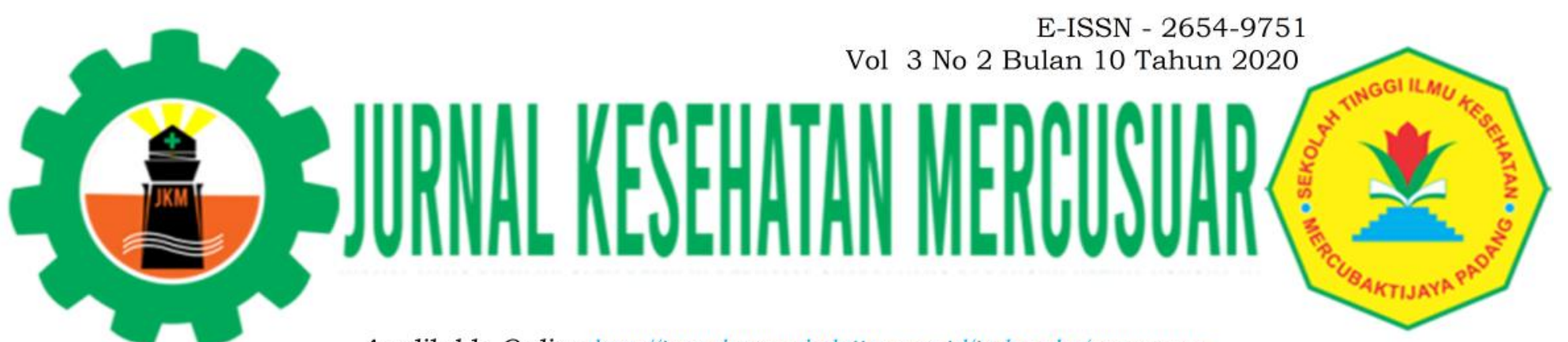

Avalilable Online http://jurnal.mercubaktijaya.ac.id/index.php/mercusuar

\title{
Hubungan Aktivitas Fisik dan Kualitas Hidup Lansia Penderita Diabetes Melitus Tipe 2
}

\author{
T.Eltrikanawati ${ }^{1^{*}}$, Larasuci Arini $^{2}$, Ilma Chantika $^{3}$ \\ ${ }^{1 * 23}$ Sarjana Keperawatan dan Pendidikan Profesi Ners, Institut Kesehatan Mitra Bunda \\ *Email korespondensi: eltryikha@gmail.com
}

\begin{abstract}
Diabetes mellitus is a non-communicable disease whose prevalence continues to increase in the world, both in developed and developing countries. The increasing age can cause physiological dysfunction, including Diabetes Mellitus in the elderly. The body function disorders due to chronic diseases that decline in the elderly can have an impact on decreasing quality of life.This study aims to determine the relationship of physical activity with the quality of life of elderly people with type 2 diabetes mellitus. The research method used is descriptive analytic with cross sectional design. The sampling technique in this research is purposive sampling with 58 samples. The instrument used in this study was a GPAQ physical activity questionnaire and quality of life using a WHOQOL questionnaire. The statistical test used is the chi square test. The results showed the majority with low physical activity have a poor quality of life as many as 18 elderly (78.3\%), obtained p value of $0.001<0.05$ then $\mathrm{HO}$ is rejected and $\mathrm{Ha}$ is accepted and can be conclusions that there is a significant relationship between physical activity with the quality of life of elderly people with diabetes mellitus type II. As health workers are expected to provide education to the community, especially in the elderly about physical activity one of them is elderly exercise, because of good physical activity and regularly provide benefits for the body, especially for people with Diabetes Mellitus type 2.
\end{abstract}

Keywords: Physical Activity; Quality of life; Elderly; Type 2 Diabetes Mellitus 


\title{
T.Eltrikanawati ${ }^{1 *}$, Larasuci Arini ${ }^{2}$, Ilma Chantika ${ }^{3}$ | Hubungan Aktivitas Fisik dan Kualitas Hidup Lansia Penderita Diabetes Melitus Tipe 2
}

\begin{abstract}
ABSTRAK
Diabetes melitus merupakan salah satu penyakit kronis yang tidak menular yang prevalensinya terus mengalami peningkatan di dunia, baik di negara maju maupun negara berkembang. Bertambahnya usia dapat menyebabkan gangguan fungsi fisiologis, termasuk diabetes melitus pada lansia. Gangguan fungsi tubuh karena penyakit kronis yang dialami lansia dapat berdampak pada penurunan kualitas hidup. Tujuan penelitian adalah untuk mengetahui hubungan aktivitas fisik dengan kualitas hidup lansia penderita diabetes melitus tipe 2. Metode penelitan yang digunakan yaitu deskriptif analitik dengan menggunakan rancangan cross sectional. Teknik pengambilan sampel menggunakan purposive sampling sebanyak 58 sampel. Instrumen yang digunakan adalah kuesioner aktivitas fisik GPAQ dan kualitas hidup menggunakan kuesioner WHOQOL. Uji statistik yang digunakan adalah chi square test. Hasil penelitian dapat diperoleh bahwa lansia dengan aktivitas fisik rendah memiliki kualitas hidup tidak baik sebanyak 18 lansia (78,3\%), didapatkan nilai $p$ value 0,001 $<0,05$ maka H0 di tolak dan Ha diterima. Kesimpulannya adalah terdapat hubungan bermakna antara aktivitas fisik dengan kualitas hidup lansia penderita diabetes melitus tipe 2 . Tenaga kesehatan diharapkan dapat memberikan edukasi masyarakat khususnya lansia tentang aktivitas fisik seperti senam lansia, karena aktivitas fisik yang baik dan teratur dapat meningkatkan kualitas hidup lansia dengan diabetes melitus tipe 2.
\end{abstract}

Kata Kunci: Aktifitas Fisik; Kualitas Hidup; Lanjut Usia; Diabetes Melitus Tipe 2

\section{PENDAHULUAN}

Lanjut usia adalah suatu proses yang dialami dan tidak dapat dihindari oleh manusia. Lansia ditandai dengan perubahan fisik, emosional, dan kehidupan sosial. Gejala-gejala kemunduran fisik seperti merasa cepat sesak, stamina menurun, badan membengkok, kulit keriput, rambut memutih, gigi mulai rontok, fungsi panca indera menurun, dan pengapuran pada tulang rawan (Maramis, 2016).

Bertambahnya usia menyebabkan gangguan fungsi fisiologis mengalami penurunan akibat proses penuaan sehingga penyakit tidak menular banyak muncul pada lanjut usia. Selain itu, masalah degeneratif menurunkan daya tahan tubuh sehingga rentan terkena infeksi penyakit tidak menular, salah satunya adalah diabetes melitus tipe 2. Berbagai gangguan fungsi tersebut dapat berdampak pada kualitas hidup lansia. Berdasarkan dari hasil analisa persentase jumlah penderita diabetes melitus pada lansia di Indonesia adalah 13,8 \% (Infodatin, 2016). Penyakit yang dimiliki lansia dapat menyebabkan terjadinya penurunan kualitas hidup lansia, termasuk penyakit kronis seperti diabetes melitus tipe 2 (Lestari, 2019).Tujuan penelitian adalah untuk mengetahui hubungan aktifitas fisik dengan kualitas hidup lansia penderita diabetes melitus tipe 2.

\section{METODE PENELITIAN}

Jenis penelitian ini termasuk dalam penelitian deskriptif analitik, yang bertujuan mengetahui hubungan antara dua variabel pada situasi atau kelompok objek, dengan menggunakan rancangan cross sectional. Dengan cara pengumpulan data sekaligus pada suatu waktu (Notoatmodjo, 2017).

Sampel dalam penelitian adalah lansia dengan diabetes melitus tipe 2 yang berdomisili di wilayah kerja Botania yang berjumlah 58 orang. Teknik pengambilan 


\section{T.Eltrikanawati $^{1 *}$, Larasuci Arini' ${ }^{2}$, Ilma Chantika ${ }^{3}$ | Hubungan Aktivitas Fisik dan Kualitas Hidup Lansia Penderita Diabetes Melitus Tipe 2}

sampel dalam penelitian menggunakan teknik nonprobability sampling dengan jenis teknik pengambilan sampel yaitu purposive sampling. Penelitian dilaksanakan di wilayah kerja Puskesmas Botania Kota Batam. Waktu pengumpulan data dilakukan pada bulan September 2018 .

Teknik pengumpulan data dalam penelitian adalah dengan cara menyebarkan lembar kuisioner kepada lansia dengan diabetes melitus tipe 2 setelah diisi lengkap, maka dikumpulkan kembali oleh peneliti. Instrumen untuk variabel bebas aktivitas fisik menggunakan Global Physical Activity Questionnaire (GPAQ) sedangkan instrumen untuk variabel terikat kualitas hidup lansia menggunakan standar dari The World Health Organization Quality of Life (WHOQOL). Data yang telah terkumpul dari lembar kuesioner yang telah diisi akan diolah dengan beberapa tahap sebagai berikut: editing, coding, entry data, dan tabulation. Analisis data penelitian menggunakan uji Chi-Square.

Tabel 1. Distribusi Frekuensi Aktivitas Fisik Lansia dengan Diabetes Melitus Tipe 2

\begin{tabular}{cccc}
\hline No & Aktivitas Fisik & Frekuensi & Persentase (\%) \\
\hline 1. & Tinggi & 20 & 34,5 \\
2. & Sedang & 15 & 25,9 \\
3. & Rendah & 23 & 39,6 \\
\hline & Total & $\mathbf{5 8}$ & $\mathbf{1 0 0}$ \\
\hline
\end{tabular}

Tabel 1. menunjukkan data bahwa dari 58 lansia, sebagian besar lansia mempunyai aktivitas fisik rendah berjumlah 23 lansia $(39,7 \%)$.

Tabel 2. Distribusi Frekuensi Kualitas Hidup Lansia dengan Diabetes Melitus Tipe 2

\begin{tabular}{cccc}
\hline No. & Kualitas Hidup & Frekuensi & Persentase (\%) \\
\hline 1. & Tidak baik & 28 & 48,3 \\
2. & Baik & 30 & 51,7 \\
\hline & Total & $\mathbf{5 8}$ & $\mathbf{1 0 0}$ \\
\hline
\end{tabular}

Tabel 2. menunjukkan data bahwa mayoritas lansia memiliki kualitas hidup baik berjumlah 30 lansia $(51,7 \%)$.

Analisa Bivariat dilakukan untuk mengetahui hubungan aktivitas fisik dengan kualitas hidup lansia penderita diabetes melitus tipe 2, maka dapat tersaji pada tabel berikut:

Tabel 3. Hubungan Aktivitas Fisik dengan Kualitas Hidup Lansia Penderita Diabetes Melitus Tipe 2

\begin{tabular}{|c|c|c|c|c|c|c|c|}
\hline \multirow{3}{*}{$\begin{array}{c}\text { Aktivitas } \\
\text { Fisik }\end{array}$} & \multicolumn{4}{|c|}{ Kualitas Hidup } & \multirow{2}{*}{\multicolumn{2}{|c|}{ Total }} & \multirow{3}{*}{$\begin{array}{c}P \\
\text { Value }\end{array}$} \\
\hline & \multicolumn{2}{|c|}{ Tidak baik } & \multicolumn{2}{|c|}{ Baik } & & & \\
\hline & $\mathbf{f}$ & $\%$ & $\mathbf{f}$ & $\%$ & $\mathbf{f}$ & $\%$ & \\
\hline Tinggi & 5 & 25,0 & 15 & 75.0 & 20 & 100 & 0001 \\
\hline Sedang & 5 & 33.3 & 10 & 66,7 & 15 & 100 & 0,001 \\
\hline Rendah & 18 & 78,3 & 5 & 21,7 & 23 & 100 & \\
\hline Jumlah & 28 & 48,3 & 30 & 51,7 & 58 & 100 & \\
\hline
\end{tabular}




\section{T.Eltrikanawati $^{1^{*}}$, Larasuci Arini ${ }^{2}$, Ilma Chantika ${ }^{3}$ | Hubungan Aktivitas Fisik dan Kualitas Hidup Lansia Penderita Diabetes Melitus Tipe 2}

Berdasarkan tabel 3. Sebagian besar lansia dengan aktivitas fisik rendah memiliki kualitas hidup tidak baik sebanyak 18 lansia $(78,3 \%)$ dan lansia dengan aktivitas fisik tinggi memiliki kualitas hidup baik sebanyak 15 lansia $(75,0 \%)$. Berdasarkan hasil penelitian menunjukkan data bahwa dari 58 lansia sebagian besar memiliki aktivitas fisik rendah berjumah 23 lansia $(39,7 \%)$, aktivitas fisik tinggi berjumlah 20 lansia $(34,5 \%)$, dan aktivitas fisik sedang 15 lansia $(25,9 \%)$.

Hasil penelitian ini sejalan dengan penelitian (Timisela et al., 2017) didapatkan hasil yang memiliki aktivitas fisik ringan 23 orang $(17,4 \%)$, aktivitas fisik sedang 27 orang $(50,5 \%)$ aktivitas berat 82 orang $(62,1 \%)$. Penelitian lainnya memiliki hal yang serupa seperti penelitian Panjaitan dan Hasibuan (2013) didapatkan data bahwa 17 orang dengan aktivitas tinggi $(44,74 \%)$, aktivitas tidak tinggi 21 orang $(55,26 \%)$. Berdasarkan hasil penelitian Eltrikanawati, Nurlailah, dan Tampubolon (2020) menyatakan bahwa mayoritas pasien diabetes melitus tipe 2 mempunyai pola aktivitas yang ringan yaitu sebanyak 35 orang $(60,3 \%)$, minoritas memiliki pola aktivitas sedang sebanyak 23 orang $(39,7 \%)$.

Aktivitas fisik adalah kegiatan yang biasa dilakukan sehari-hari, seperti aktivitas umum, aktivitas rumah tangga/domestik, aktivitas yang berkaitan dengan penggunaan transportasi, bekerja, olahraga, dan aktivitas lainnya yang dilakukan di waktu senggang selama 24 jam. Aktivitas fisik merupakan salah satu tatalaksana terapi diabetes melitus dari segi non-farmakologis yang dianjurkan. Aktivitas fisik yang direkomendasikan oleh WHO yang bertujuan untuk memperbaiki kesehatan kardiorespirasi dan kebugaran otot, kesehatan tulang, dan menurunkan risiko Penyakit Tidak
Menular (PTM) serta depresi (Nur, Wilya, \& Ramadhan, 2016).

Hasil penelitian ini menujukkan dari 58 lansia sebagian besar dengan kualitas hidup baik berjumlah 30 responden (51,7\%), kualitas hidup tidak baik 28 responden $(48,3)$. Penelitian ini sejalan dengan penelitian Timisela et al. (2017) didapatkan data bahwa 101 orang dengan memiliki kualitas hidup yang baik (76,5\%), kualitas hidup kurang buruk sebanyak 31 orang $(23,5 \%)$. Berdasarkan penelitian Laoh dan Tampongangoy (2015) menunjukkan hasil yang sama bahwasanya kulitas hidup pasien diabetes melitus memiliki kualitas hidup dalam kategori yang baik sebanyak 19 responden $(63,3 \%)$ dan yang memiliki kualitas hidup dalam kategori kurang baik sebanyak 11 responden $(36,7 \%)$.

Kualitas hidup (quality of life) digunakan dalam bidang pelayanan kesehatan untuk menganalisis emosional seseorang, faktor sosial, dan kemampuan untuk memenuhi tuntutan kegiatan dalam kehidupan secara normal dan dampak sakit dapat berpotensi untuk menurunkan kualitas hidup terkait kesehatan (Sari \& Yulianti, 2017). Kualitas hidup memiliki peranan yang penting dalam mengelola penyakit. Peningkatan kualitas hidup pasien diabetes melitus salah satunya dapat dilakukan dengan melakukan terapi fisik (Noorratri \& Leni, 2019).

Hasil analisa statistik uji Chi- square test diperoleh nilai $p$ value sebesar $0.001<$ 0.05 . Hal ini berarti menunjukkan ada hubungan yang signifikan antara aktivitas fisik dengan kualitas hidup lansia penderita diabetes melitus tipe 2. Hasil penelitian ini sejalan dengan penelitian Timisela et al. (2017) menunjukkan bahwa nilai $p$ sebesar $0,000(p<0,05)$. Hal ini menunjukkan adanya hubungan antara aktivitas fisik dengan kualitas hidup penderita diabetes melitus tipe 2 . 


\section{T.Eltrikanawati $^{1 *}$, Larasuci Arini ${ }^{2}$, Ilma Chantika ${ }^{3}$ | Hubungan Aktivitas Fisik dan Kualitas Hidup Lansia Penderita Diabetes Melitus Tipe 2}

Berdasarkan hasil penelitian Siti dan Muflihatin (2017) menunjukkan data bahwa hasil uji statistik yang signifikan yaitu $p$ - value $=0.014<=0.05$. Maka H0 ditolak dan $\mathrm{Ha}$ diterima dan terdapat hubungan yang bermakna antara latihan fisik dengan kualitas hidup pasien diabetes melitus tipe 2 .

Berdasarkan dari penelitian ini menunjukkan perlu adanya pemberian pendidikan kesehatan mengenai aktivitas fisik pada lansia secara teratur sebab dapat meningkatkan kualitas hidup lansia dengan diabetes melitus tipe 2. Maka bagi petugas kesehatan yang bekerja di pelayanan kesehatan seperti Rumah Sakit, Puskesmas khususnya pada program posyandu lansia sangat dianjurkan merencanakan atau membuat jadwal aktivitas fisik salah satunya senam lansia dan pemberian edukasi terkait pentingnya aktivitas fisik lansia secara teratur kepada lansia yang menderita diabetes melitus tipe 2 untuk meningkatkan kualitas hidup lansia menjadi lebih baik dan bermakna dalam menjalani kehidupannya pada lanjut usia.

\section{SIMPULAN}

Berdasarkan hasil penelitian yang dilakukan dapat diambil kesimpulan bahwa terdapat hubungan yang signifikan antara aktifitas fisik dengan kualitas hidup lansia penderita diabetes melitus tipe 2 .

\section{UCAPAN TERIMAKASIH}

Penulis mengucapkan terimakasih kepada Kepala Puskesmas Botania, perawat Puskesmas Botania, dan civitas akademika Institut Kesehatan Mitra Bunda yang telah memberikan dukungan baik moril maupun materil selama pelaksanaan penelitian.

\section{DAFTAR PUSTAKA}

Eltrikanawati, Nurlailah, Tampubolon, M. (2020). Hubungan Pola Makan dan Pola Aktifitas Fisik Terhadap Kadar
Gula Darah Pada Pasien Diabetes Mellitus Tipe 2. Jurnal Ilmiah Keperawatan Imelda, 6(2), 0-6.

Infodatin. (2016). Sustamycin and tetrabid: slow-release tetracyclines. In Drug and Therapeutics Bulletin (Vol. 10, Issue 16).

Laoh, J., \& Tampongangoy, D. (2015). Gambaran Kualitas Hidup Pasien Diabetes Mellitus Di Poliklinik Endokrin RSUP PROF. Dr. R. D. Kandao Manado. Jurnal Ilmiah Perawat Manado, 4(1), 92587.

Lestari, febri. (2019). Depresi dan Kualitas Hidup Pasien Diabetes Mellitus di Wilayah Puskesmas Buayan, Kabupaten Kebumen. STIKes Muhammadiyah Gombong.

Maramis, R. L. (2016). Kebermaknaan Hidup Dan Kecemasan Dalam Menghadapi Kematian Pada Lansia Di Panti WerdhaSamarinda. EJournal Psikologi, 4, 319-332.

Noorratri, Erika Dewi; \& Leni, A. S. M. (2019). Peningkatan Kualitas Hidup Pasien Diabetes Mellitus Dengan Terapi Fisik. Jurnal Ilmu Keperawatan Komunitas, 2(1), 19.

Notoatmodjo, \& Soekidjo. (2018). Metodologi penelitian kesehatan / Soekidjo Notoatmodjo. Koleksi Buku UPT Perpustakaan Universitas Negeri Malang, O(0), 2-7.

Nur, Wilya, Ramadhan, R. (2016). Kebiasaan Aktifitas Fisik Pasien Diabetes MellitusTerhadap Kadar Gula Darah Di Rumah. SEL, 3(2), 41-48.

Panjaitan, Hasibuan, H. (2013). Hubungan Antara Aktifitas Fisik Dan Kualitas Hidup Pasien Diabetes Mellitus Tipe 2 Di Puskesmas Purnama Kecamatan Pontianak Selatan Kota Pontianak. Universitas Tanjungpura.

Sari, R. A., \& Yulianti, A. (2017). Mindfullness dengan kualitas hidup 
pada lanjut usia. Jurnal Psikologi UIN Sultan Syarif Kasim, 13(1), 4854.

Siti, W., \& Muflihatin, K. (2017). Windiarti Siti Khoiroh Muflihatin. STIKes Muhammadiyah Samarinda.

Timisela, J. C., Ratag, B. T., \& Kalesaran,
A. F. C. (2017). Hubungan Aktivitas Fisik dengan Kualitas Hidup Pasien DM Tipe II di RSU Pancaran Kasih. Jurnal Media Kesehatan, 9(3), 1-6. WHO. (2009). WHO QOL BREF instrument. WHO, 5, 14-17. 